\title{
RESEARCH
}

Open Access

\section{Paclitaxel-activated astrocytes produce mechanical allodynia in mice by releasing tumor necrosis factor-a and stromal- derived cell factor 1}

Xiaojuan Liu' ${ }^{1,2+}$, Raquel Tonello ${ }^{1+}$, Yuejuan Ling ${ }^{1,3}$, Yong-Jing Gao ${ }^{3,4}$ and Temugin Berta ${ }^{1 *}$ (D)

\begin{abstract}
Background: Paclitaxel is a widely used and potent chemotherapeutic agent for the treatment of cancer. However, patients receiving paclitaxel often develop an acute pain syndrome for which there are few treatment options. Astrocytes play an important role in the pathogenesis of pain in multiple preclinical models, as well as in paclitaxeltreated rodents. However, it is still unclear what the exact contribution of astrocytes may be in paclitaxel-associated acute pain syndrome (P-APS).
\end{abstract}

Methods: P-APS was modeled by a single systemic or intrathecal injection of paclitaxel and astrocyte contribution tested by immunohistochemical, pharmacological, and behavioral approaches. Cell cultures were also prepared to assess whether paclitaxel treatment directly activates astrocytes and whether intrathecal injection of paclitaxeltreated astrocytes produces pain that is reminiscent of P-APS.

Results: Systemic injection of paclitaxel resulted in increased expression of glial fibrillary acidic protein (a common marker of astrocytic activation), as well as both systemic or intrathecal injection of paclitaxel induced pain hypersensitivity indicated by the development of mechanical allodynia, which was significantly reversed by the astrocytic inhibitor L-a-AA. Cultured astrocytes were activated by paclitaxel with significant increases in protein levels for tumor necrosis factor-a (TNF-a) and stromal-derived cell factor 1 (SDF-1). Importantly, intrathecal injection of paclitaxel-activated astrocytes produced mechanical allodynia that was reversed by TNF-a and SDF-1 neutralizing antibodies.

Conclusion: Our results suggest for the first time that paclitaxel can directly activate astrocytes, which are sufficient to produce acute pain by releasing TNF-a and SDF-1. Targeting astrocytes and these cytokines may offer new treatments for P-APS.

Keywords: Paclitaxel-associated acute pain syndrome, Paclitaxel, Neuroinflammation, Astrocytes, Tumor necrosis factor, Stromal-derived cell factor

\footnotetext{
* Correspondence: temugin.berta@uc.edu

'Xiaojuan Liu and Raquel Tonello contributed equally to this work.

'Department of Anesthesiology, Pain Research Center, University of

Cincinnati College of Medicine, Cincinnati, OH, USA

Full list of author information is available at the end of the article
}

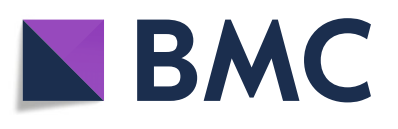

(c) The Author(s). 2019 Open Access This article is distributed under the terms of the Creative Commons Attribution 4.0 International License (http://creativecommons.org/licenses/by/4.0/), which permits unrestricted use, distribution, and reproduction in any medium, provided you give appropriate credit to the original author(s) and the source, provide a link to the Creative Commons license, and indicate if changes were made. The Creative Commons Public Domain Dedication waiver (http://creativecommons.org/publicdomain/zero/1.0/) applies to the data made available in this article, unless otherwise stated. 


\section{Background}

The American Cancer Society estimated that 1.7 million people would be diagnosed with cancer in 2018 and that more than 15.5 million people are living with a history of cancer in the USA today. Paclitaxel (i.e., Taxol and Onxal) is one of the most effective chemotherapeutic drugs, widely used for the treatment of solid cancers such as ovarian, breast, and lung carcinoma [1]. However, paclitaxel is associated with a peculiar syndrome of acute pain, which is described in up to $70 \%$ of patients and usually develops within 1 to 3 days of its administration $[2,3]$. Although the paclitaxel-associated acute pain syndrome (P-APS) is distinguished by nature and temporal profile from paclitaxel-induced peripheral neuropathy [4], a potential relationship may exist between these two entities and drug doses [2, 4, 5]. It has been reported that patients with higher and uncontrolled PAPS are at higher risk to develop chronic neuropathy [2]. Unfortunately, current therapeutic approaches for PAPS and peripheral neuropathy are limited, and often dose reduction or termination of the treatment are the only options, potentially affecting the optimal care of these patients $[2,6]$. Identification of target-directed therapeutic approaches based on mechanistic insights is of paramount significance to improve the treatment of cancer patients $[7,8]$.

Peripheral neuropathological changes in response to chemotherapeutic drugs are considered the provocative processes for the development of P-APS and peripheral neuropathy [9-11]. However, paclitaxel pain emerges long before deficits in peripheral sensory nerve function and at a dose that causes any nerve deficits $[1,12,13]$. Accumulating evidence is emerging of important roles for glial cells (i.e., satellite glial cells, microglia, and astrocytes) in these syndromes [14-17]. In particular, there is strong evidence for early activation and contribution of astrocytes to peripheral neuropathy [18-20]. Concordantly, pharmacological blockade of astrocytes with general inhibitors of glial cells has been shown to significantly attenuate chemotherapy-induced neuropathic pain in rodents $[18,20,21]$, but the fine molecular mechanisms underlying their activation and contribution to P-APS are still incompletely known.

Systemic injection of paclitaxel induces a rapid and persistent activation of spinal astrocytes assessed by increase of glial fibrillary acidic protein (GFAP), a common marker for astrocyte activation [14], and downregulation of astrocytic glutamate transporters [18, 20]. Furthermore, paclitaxel induces robust increases of the phosphorylation of c-jun N-terminal kinase (p-JNK) [20], a member of the mitogen-activated protein kinase family that is associated with astrocytic cytokine production, enhancing the hyperactivity in the spinal pain circuits and promoting neuropathic pain $[22,23]$.
To date, it is unclear how paclitaxel directly activates astrocytes and whether this activation is sufficient to induce pain. Given that astrocytic end-feet ensheath the microvasculature, small amounts of paclitaxel can cross the blood-brain barrier, and paclitaxel was detected in cerebral fluid [24, 25], we hypothesize that small amounts of paclitaxel are sufficient to directly activate astrocytes and thus elicit P-APS. Here, we show for the first time that small amounts of spinal paclitaxel are sufficient to induce pain hypersensitivity via astrocytes and that paclitaxel directly elicits astrocyte activation and production cytokines that may underlie the paclitaxelassociated acute pain syndrome.

\section{Materials and methods}

\section{Animals}

Wild-type CD1 mice (115 male and 20 female mice, 8-10 weeks old for in vivo studies and P1-3 for in vitro studies) were purchased from Charles River and used as indicated for behavioral, cell culture, and biochemical experiments. Mice were housed four per cage at $22 \pm 0.5{ }^{\circ} \mathrm{C}$ under a controlled $14 / 10 \mathrm{~h}$ light/ dark cycle with free access to food and water. All animal procedures were approved by the University of Cincinnati Institutional Animal Care and Use Committee, and all efforts were made to minimize animal suffering, reduce the number of animals used, and use alternatives to in vivo techniques, in accordance with the International Association for the Study of Pain, the National Institutes of Health Office of Laboratory Animal Welfare Guide for the Care and Use of Laboratory Animals.

\section{Chemotherapeutic treatment}

Paclitaxel $(6 \mathrm{mg} / \mathrm{ml})$ in $50 \%$ El Kolipher (MilliporeSigma, St. Louis, MO) and 50\% ethanol (Sigma-Aldrich) were diluted in sterile saline and administered intraperitoneally (i.p.) at a dose of $2 \mathrm{mg} / \mathrm{kg}$ [26] or intrathecally (i.t.) at a dose of $50 \mathrm{nM}$ in $5 \mu \mathrm{l}$ of phosphate-buffered saline (PBS) solutions. Control animals received an equivalent volume of the vehicle with proportional amounts of Cremophor EL and 95\% dehydrated ethanol diluted in PBS. Signs of peripheral neuropathy with a similar phenotype to that in patients have been validated by multiple investigators in this non-tumor-bearing animal model, including an early and time-dependent development of mechanical and cold allodynia [25, 27, 28].

\section{Von Frey test for mechanical allodynia}

Mechanical allodynia as a readout for CIPN was assessed as the hind paw withdrawal response to von Frey hair stimulation using the up-and-down method, as previously described [29]. Briefly, the mice were first acclimatized $(1 \mathrm{~h})$ in individual clear Plexiglas boxes on an elevated wire mesh platform to facilitate access to the 
plantar surface of the hind paws. Subsequently, a series of von Frey hairs $(0.02,0.07,0.16,0.4,0.6,1.0$, and $1.4 \mathrm{~g}$; Stoelting CO., Wood Dale, IL) were applied perpendicular to the plantar surface of hind paw. A test began with the application of the $0.6 \mathrm{~g}$ hair. A positive response was defined as a clear paw withdrawal or shaking. Whenever a positive response occurred, the next lower hair was applied, and whenever a negative response occurred, the next higher hair was applied. The testing consisted of six stimuli, and the pattern of response was converted to a $50 \%$ von Frey threshold, using the method described previously [30], by an investigator blinded to treatment until the end of the experiment.

\section{Cold plantar test for cold allodynia}

The cold plantar assay was used to evaluate noxious cold [26, 31]. Briefly, animals were first placed individually into clear acrylic containers separated by black opaque dividers that were set on top of 3/160 borosilicate glass (Stemmerich Inc., St. Louis, MO) and allowed to acclimate for $20 \mathrm{~min}$ before testing. A dry ice pellet was applied to the hind paw through the glass and the time until hind paw withdrawal was recorded at 5-min intervals per mice, alternating paws, for a total of three trials, and the mean withdrawal latency was calculated by an investigator blinded to treatment until the end of the experiment.

\section{Drugs and intrathecal administration}

For intrathecal injection, spinal puncture was made with a 30-gauge needle between the L5 and L6 level to deliver the reagents, as previously described [32-34]. We purchased the astrocyte inhibitor L- $\alpha$-aminoadipate (L- $\alpha$ AA) from Millipore-Sigma and administrated i.t. at a concentration of $50 \mathrm{nmol}$ in $5 \mu \mathrm{l}$ of PBS. Specific inhibitors PD98059 (Millipore-Sigma) targeting the upstream ERK kinase and SP600125 (Selleckchem, Houston, TX) targeting JNK kinase were used at doses reported in previous studies $[22,35]$. Neutralizing antibodies for TNF- $\alpha$ (Catalog \# AF-410) and SDF-1 (Catalog \# MAB350) were purchased from R\&D Systems (Minneapolis, MN) and administrated i.t. at $5 \mu \mathrm{g} /$ site. Goat and mouse IgG (Santa Cruz Biotechnology, Dallas, TX) were respectively used at the same dose as controls.

\section{Astrocyte culture and intrathecal administration}

To get high quality and large quantity of astrocytes, we prepared most astrocyte cultures from cerebral cortexes of post-neonatal mice (1-3 days old). The cerebral hemispheres were isolated and transferred to ice-cold Hank's buffer, and the meninges were carefully removed. Tissues were then minced into about $1 \mathrm{~mm}$ pieces, triturated, filtered through 100 - and then $40-\mu \mathrm{m}$ strainers, and collected by centrifugation at $1000 \mathrm{~g}$ for $5 \mathrm{~min}$. The cell pellets were broken with a pipette and resuspended in a medium containing $10 \%$ fetal bovine serum (FBS) in low-glucose DMEM (Thermo Fisher, Waltham, MA). After trituration, the cells were filtered through a $10-\mu \mathrm{m}$ strainer, plated into six-well plates at a density of $2.5 \times$ $10^{5}$ cells $/ \mathrm{cm}^{2}$ or onto cover glasses for immunohistochemistry, and cultured for 10-12 days. The medium was replaced twice a week and once were grown to $95 \%$ confluence (about 10 days); $0.15 \mathrm{mM}$ dibutyryl-cAMP (Millipore-Sigma) was added to induce differentiation. Three days later, the cells were used for immunohistochemistry, Western blot, and quantitative real-time RTPCR or intrathecal injection experiments. Cultures were incubated with paclitaxel, recombinant TNF- $\alpha$ (R\&D Systems), TLR4 inhibitor TLR4-IN-C34 (C34, Catalog \# SML0832, Millipore-Sigma), or appropriate control solutions. For intrathecal injections, cultured astrocytes were harvested using $0.025 \%$ trypsin (Thermo Fisher) $1 \mathrm{~h}$ after vehicle or paclitaxel and washed thoroughly three times with PBS and centrifuged at $1000 \mathrm{~g}$ for $5 \mathrm{~min}$. About $2-4 \times 10^{4}$ astrocytes in $10 \mu \mathrm{l}$ of PBS were injected intrathecally between the L5 and L6 spinal levels with a 30-G needle to deliver the cells into the CSF, as previously described [36].

\section{Cell viability assay}

Astrocyte culture were replated at same concentration $\left(2.5 \times 10^{5} \mathrm{cell} / \mathrm{ml}\right)$ and assessed for their viability $24 \mathrm{~h}$ after exposure to vehicle, paclitaxel, and TNF- $\alpha$ using the resazurin-based PrestoBlue ${ }^{\diamond}$ Cell Viability Reagent (Thermo Fisher). Briefly, $50 \mu$ l of PrestoBlue ${ }^{\circledR}$ reagent was added to culture media for $30 \mathrm{~min}$ and $200 \mu \mathrm{l}$ of media collected for absorbance quantification. Absorbance was measured at $600 \mathrm{~nm}$ using an EnVision plate reader (PerkinElmer, Waltham, MA).

\section{Immunofluorescence}

Deeply anesthetized mice were perfused through the left ventricle of the heart with PBS, followed by $4 \%$ paraformaldehyde in PBS (PFA solution), and lumbar (L3-L5) spinal cord segment was removed and post-fixed in PFA solution overnight. Spinal cord tissues were transferred into $30 \%$ sucrose in PBS for $24 \mathrm{~h}$, and then were sliced into $30-\mu \mathrm{m}$ sections using a cryostat. For astrocyte cultures, cells were fixed with PFA solution for $20 \mathrm{~min}$, washed with PBS, and processed for immunofluorescence. Spinal cord sections or astrocyte cultures were blocked for $1 \mathrm{~h}$ at room temperature with $1 \%$ BSA with $0.2 \%$ Triton X-100 in PBS (BSA solution) and incubated with glial fibrillary acidic protein primary antibody (GFAP, mouse, 1:500, Catalog \# MAB360, MilliporeSigma) overnight at $4{ }^{\circ} \mathrm{C}$, followed by incubation with the secondary antibody anti-rabbit Alexa Fluor 546 (1: 1000, Thermo Fisher) for $1 \mathrm{~h}$ at room temperature. 
Images were captured under an Olympus BX63 fluorescent microscope using cellSens imaging acquisition software (Olympus, Center Valley, PA). A region of interest was drawn with cellSens within the dorsal horn including laminas I and II (Fig. 1a), and intensity quantifications of GFAP signal were performed comparing samples from all experimental groups, prepared with the same staining solutions, then measured using identical display parameters. Five to eight randomly selected spinal cord sections were used from each experimental animal, and background of a region outside of the tissue section and the area of the region of interest were used for normalization and quantification purposes, as previously described [18].

\section{Western blotting}

Astrocyte culture was homogenized in a RIPA lysis buffer (Millipore-Sigma) complemented with a solution containing protease and phosphatase inhibitors (MS-
SAFET, Millipore-Sigma). Protein samples were quantified using the Qubit ${ }^{\circ}$ Protein Assay Kit (Thermo Fisher) according to the instruction of manufacturers, separated on SDS-PAGE gel (4-12\% Bis-Tris Plus Gels, Thermo Fisher) and transferred to PVDF blots (Millipore-Sigma). Blots were blocked with Odyssey blocking buffer (TBS, LI-COR Biosciences, Lincoln, NE) and then probed with antibodies against p-JNK (rabbit, 1:500, Catalog \# 9211, Cell Signaling, Danvers, MA) and glyceraldehyde 3phosphate dehydrogenase (GAPDH, mouse, 1:10000, Catalog \# ab8245, Abcam, Cambridge, MA) overnight. Blots were then washed and incubated with appropriate secondary fluorescent antibodies (LI-COR Biosciences) for $1 \mathrm{~h}$ at RT. Blot images were obtained by Odyssey CLx Imagine system (LI-COR Biosciences) and processed by Imagine Studio software (LI-COR Biosciences). The density of protein bands was analyzed with Image software (National Institutes of Health, Bethesda, MD).

\section{A}
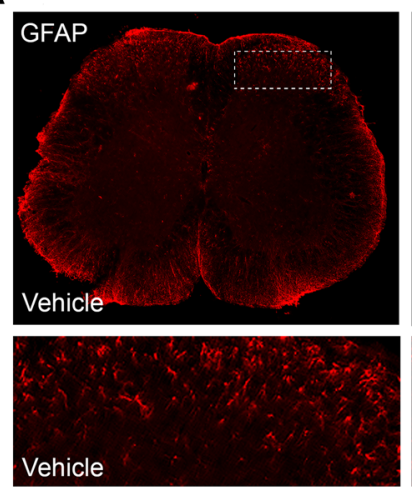

C

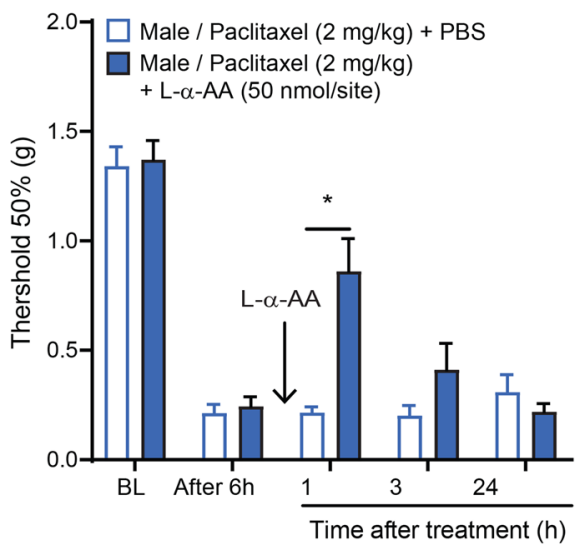

$B$
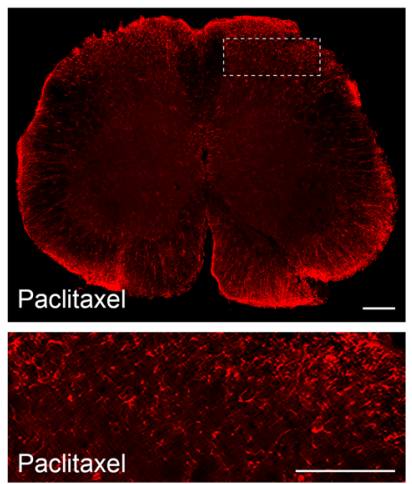

GFAP

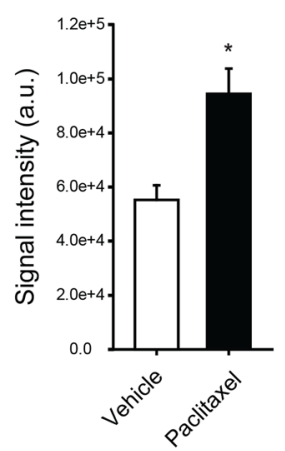

\section{D}

Mechanical allodynia

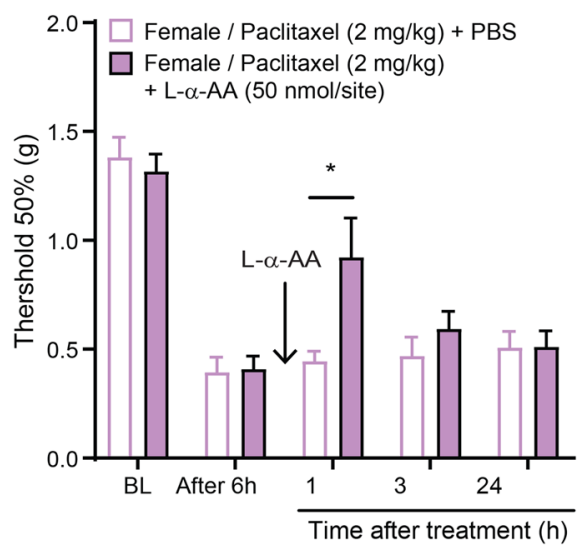

Fig. 1 Systemic paclitaxel activates spinal astrocytes leading to mechanical allodynia. a Immunofluorescence showing GFAP expression in spinal cord sections of male mice $6 \mathrm{~h}$ after a single intraperitoneal (i.p.) injection of a vehicle control or paclitaxel in male mice. Dotted squares delineate quantification and magnified areas. Scale bar $=200 \mu \mathrm{m}$. b Quantification of immunofluorescence intensity of GFAP in the dorsal horn of the spinal cord, as delineated in $\mathbf{a}\left({ }^{*} P<0.05\right.$ compared to vehicle, $t$ test, $n=5$ per group). $\mathbf{c}$, d Effect of intrathecal (i.t.) administration of the astrocytic inhibitor L-a-AA on mechanical allodynia induced by i.p. injection of paclitaxel in both male (c) and female (d) mice ${ }^{*} P<0.05$ compared to vehicle, ANOVA, $n=5$ per group). BL baseline 
Enzyme-linked immunosorbent assay (ELISA)

Protein samples were prepared in the same way as for Western blot analyses, and concentration determined by BCA Protein Assay (Pierce). Mouse TNF- $\alpha$ ELISA kit was purchased from R\&D Systems, $50 \mu \mathrm{g}$ of proteins was used, and ELISA was performed according to the protocol of the manufacturer. The standard curve was included in each experiment.

\section{Cytokine array}

Protein samples were prepared in the same way as for Western blot analyses. We used the mouse Proteome ProfilerTM Arrays (Catalog \# ARY006, R\&D Systems) according to the protocol provided by the manufacturer, and cytokine expression levels were measured from four pooled samples. Samples were pooled to obtain the required amount and volume to cover the membranes and for a reliable use of the aforementioned arrays. Arrays were incubated with IRDye $800 \mathrm{CW}$ Streptavidin antibody (1:1000, Catalog \# 926-32230, LI-COR Biosciences) and images Odyssey CLx Imagine system (LI-COR Biosciences) and processed by Imagine Studio software (LI-COR Biosciences). Protein densities were normalized by each individual array backgrounds and analyzed with ImageJ software (National Institutes of Health, Bethesda, MD).

\section{Quantitative real-time RT-PCR (qPCR)}

Cultured astrocytes were lysed in TRIzol ${ }^{\mathrm{Tm}}$ Reagent (Thermo Fisher), and total RNA was extracted using Direct-zol RNA MiniPrep kit (Zymo Research, Irvine, CA), which amount and quality were assessed by SimpliNano UV-Vis Spectrophotometer (General Electric, Boston, MA), and then converted into cDNA using a high-capacity cDNA reverse transcription kit (Thermo Fisher). Specific primers for GFAP, GAPDH, and various glutamate transporters as well as cytokines were obtained from PrimerBank [37]. Primer sequences are depicted in Additional file 3: Table S1. qPCR was performed on a QuantStudio ${ }^{\text {TM }} 3$ Real-Time PCR System (Thermo Fisher Scientific) using PowerUp SYBR ${ }^{\mathrm{mm}}$ Green Master Mix (Thermo Fisher Scientific). All samples were analyzed at least in duplicate and normalized by GAPDH expression, and the relative expression ratio per condition was calculated based on the method described by Pfaffl et al. [38, 39].

\section{Statistical analysis}

Prism 8 software (Graphpad, La Jolla, CA) was used for statistical analysis. All data were expressed as mean \pm SEM. Biochemical data were analyzed using Student's $t$ test or one-way analysis of variance (ANOVA) followed by Dunn's post hoc test. Two-way repeated measured ANOVA was used to analyze multiple group data with multiple time points with Bonferroni post hoc test to determine on which days experimental groups differed. The criterion for statistical significance was set at $P<0.05$.

\section{Results \\ Paclitaxel activates spinal astrocytes leading to mechanical allodynia}

To determine the activation of spinal astrocytes, we measured the protein levels of glial fibrillary acidic protein (GFAP) in spinal cord sections $6 \mathrm{~h}$ after systemic treatment of paclitaxel or vehicle solution (Fig. 1a). Immunofluorescence showed that paclitaxel induced a significant increase of GFAP in the superficial laminae of dorsal horn of the mouse spinal cord (area defined in Fig. 1a and quantified in Fig. 1b), which is consistent with findings in rat spinal cord sections reported in a previous study [18]. Although the expression of GFAP was only quantified in the superficial laminae of the spinal dorsal horn, a strong GFAP signal seems generalized to the whole spinal cord tissue including in areas surrounding the central canal and in the white matter of the spinal cord (Fig. 1a). Interestingly, these areas are intimately in contact with the cerebrospinal fluid (CSF), and although it is generally believed that paclitaxel does not cross the blood-brain barrier, low concentrations of paclitaxel can be detected in spinal cord tissue and CSF $[24,25]$. Intrathecal injection into CSF of the astrocytic inhibitor $\mathrm{L}-\alpha$-aminoadipate (L- $\alpha-\mathrm{AA})$ is known to inhibit astrocyte activation and alleviate nerve injury- and inflammation-induced mechanical allodynia [23, 40]. We next examined whether mechanical allodynia elicited by paclitaxel would be inhibited by this intrathecal injection of the astrocytic inhibitor. We found that L- $\alpha$-AA significantly reduced the development of mechanical allodynia evoked by systemic injection of paclitaxel in both male and female mice (Fig. 1c), similarly to a previous report for another chemotherapeutic agent [21].

\section{Intrathecal injection of paclitaxel elicits mechanical allodynia via astrocytes}

The possibility of a direct spinal action of paclitaxel on astrocytes and mechanical allodynia was next tested by intrathecal injection of a low concentration of this chemotherapeutic agent (Fig. 2a). A concentration of $50 \mathrm{nM}$ of paclitaxel was detected in spinal cord tissue [41] and increased mEPSC frequency in superficial dorsal horn neurons [25]. In line with this previous observation, we found that a single intrathecal injection of $50 \mathrm{nM}$ of paclitaxel in $5 \mu \mathrm{l}$ of PBS was sufficient to elicit a significant reduction in paw withdrawal threshold to mechanical stimuli, indicating the development of mechanical allodynia (Fig. 2b). This allodynia developed at $1 \mathrm{~h}$ and lasted for up to $6 \mathrm{~h}$. In contrast, the same intrathecal 


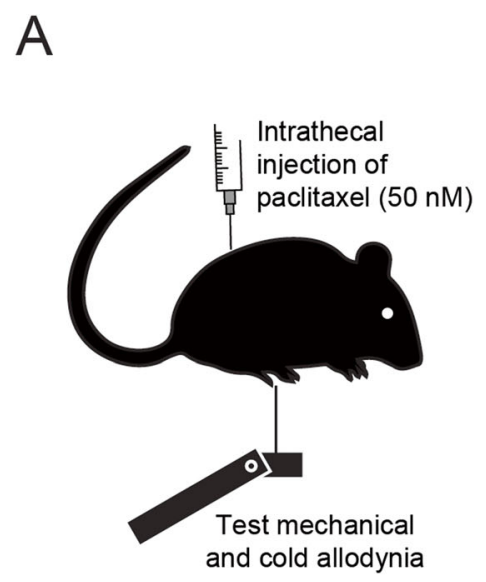

C

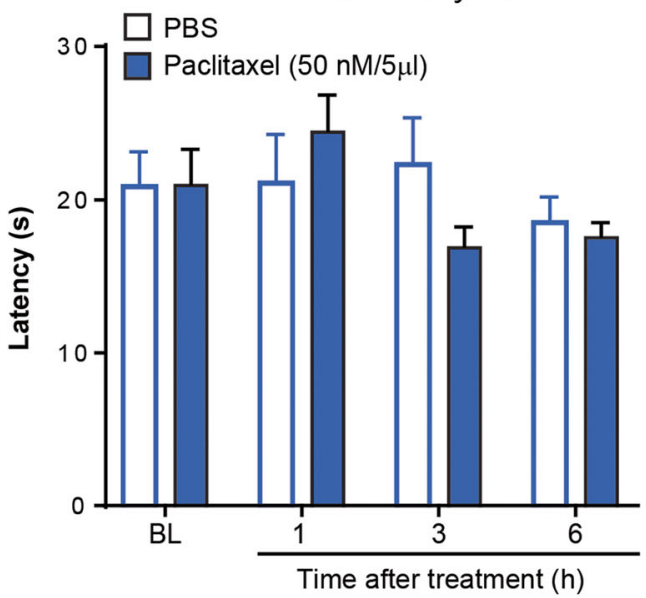

$E$

Mechanical allodynia (MEK inh.)

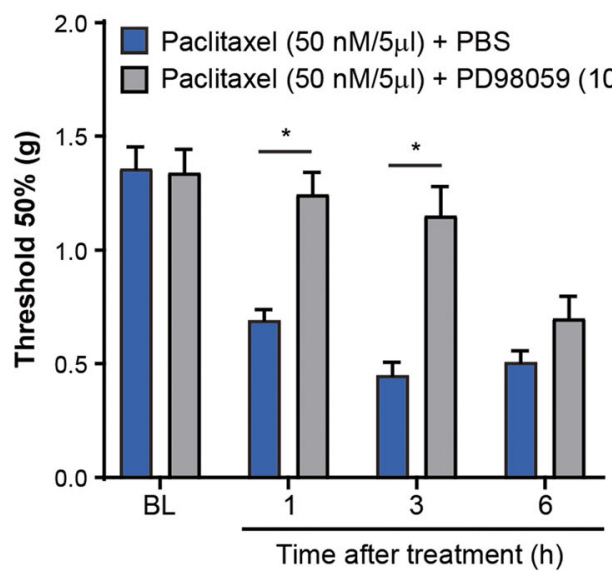

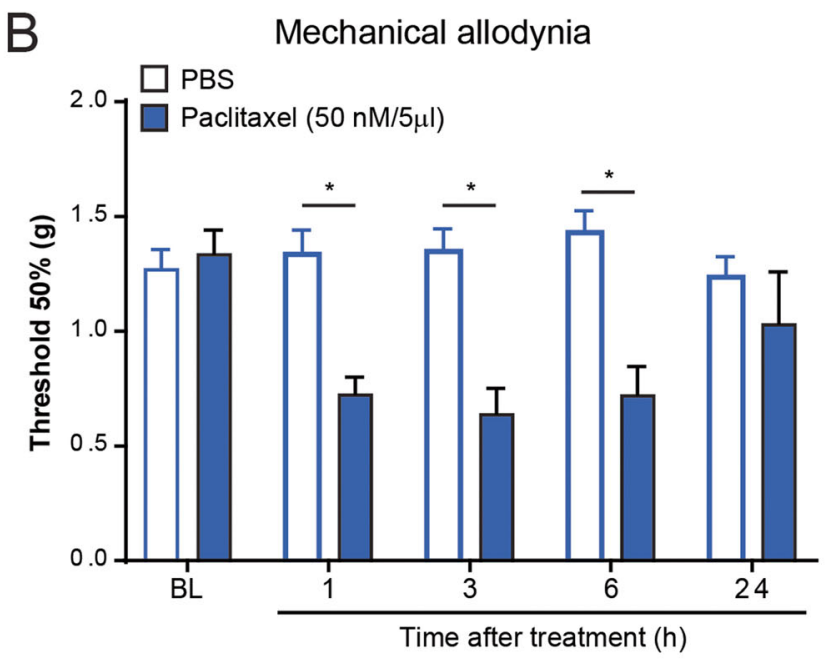

D Mechanical allodynia (L- $\alpha-A A)$

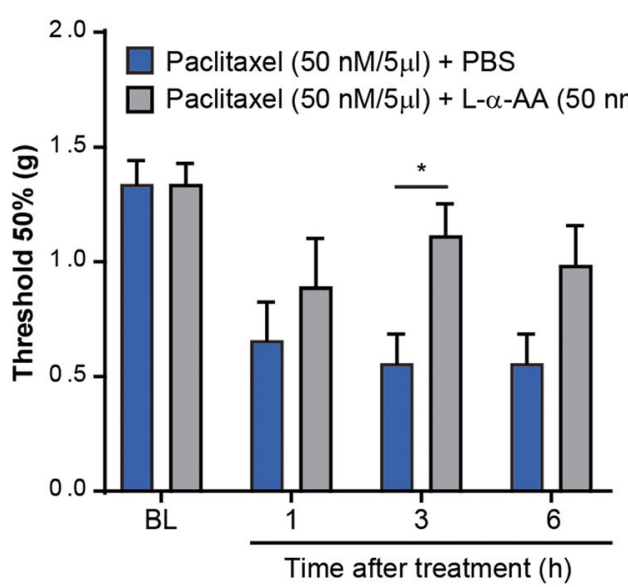

F

Mechanical allodynia (JNK inh.)

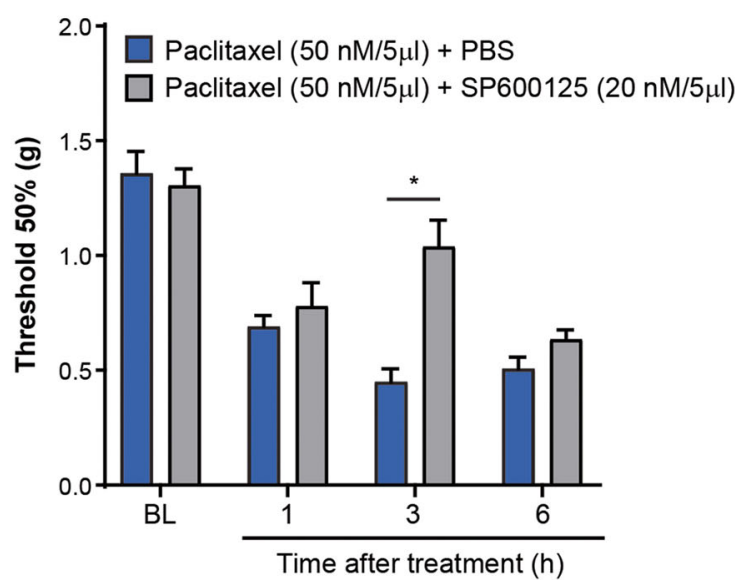

Fig. 2 (See legend on next page.) 
(See figure on previous page.)

Fig. 2 Intrathecal injection of paclitaxel elicits mechanical allodynia via astrocyte signaling. a Schematic illustration showing the experimental conditions and behavioral tests. $\mathbf{b}$, c Effect of intrathecal injection of low amount paclitaxel on mechanical and cold allodynia in male mice $\left({ }^{*} P<\right.$ 0.05 compared to vehicle, ANOVA, $n=5$ per group). BL baseline. $\mathbf{d}-\mathbf{f}$ Effect of intrathecal (i.t.) administration of the astrocytic inhibitor $L-a-A A(\mathbf{d})$, as well as MEK (e) and JNK (f) inhibitors on mechanical allodynia induced by i.t. injection of paclitaxel in male mice $\left({ }^{*} P<0.05\right.$ compared to PBS solution, ANOVA, $n=5$ per group). BL baseline

injection of paclitaxel showed no effect in paw withdrawal threshold to cold stimuli, indicating the absence of a cold allodynia (Fig. 2c). Notably, intrathecal injection of a vehicle control had no effect on both paw withdrawal thresholds (Fig. 2b, c). Similar to our previous result using the astrocytic inhibitor $\mathrm{L}-\alpha-\mathrm{AA}$, we found that this inhibitor also significantly reduced the development of mechanical allodynia evoked by intrathecal injection of paclitaxel (Fig. 2d). Various mitogen-activated protein kinase (MAPK) family members are activated in spinal glial cells after nerve injury [14]. In particular, ERK is activated sequentially in microglia and astrocytes, and JNK is activated persistently in astrocytes [23, 35].
Intrathecal injection of the ERK kinase signaling inhibitor $(10 \mu \mathrm{g} / \mathrm{site})$ or JNK inhibitor SP600125 $(20 \mathrm{nM} / 5 \mu \mathrm{l})$ both significantly reversed the paclitaxel-induced mechanical allodynia (Fig. 2e, f). These findings suggest that low concentrations of paclitaxel are sufficient to induce mechanical allodynia partially via astrocytic signaling.

\section{Paclitaxel induces the activation of cultured astrocytes independently from TLR4 signaling}

To determine whether paclitaxel can directly activate astrocytes, we stimulated primary culture of astrocytes with $50 \mathrm{nM}$ of paclitaxel or TNF- $\alpha$ (Fig. 3a). Because paclitaxel is known as a cellular toxin, we first assessed

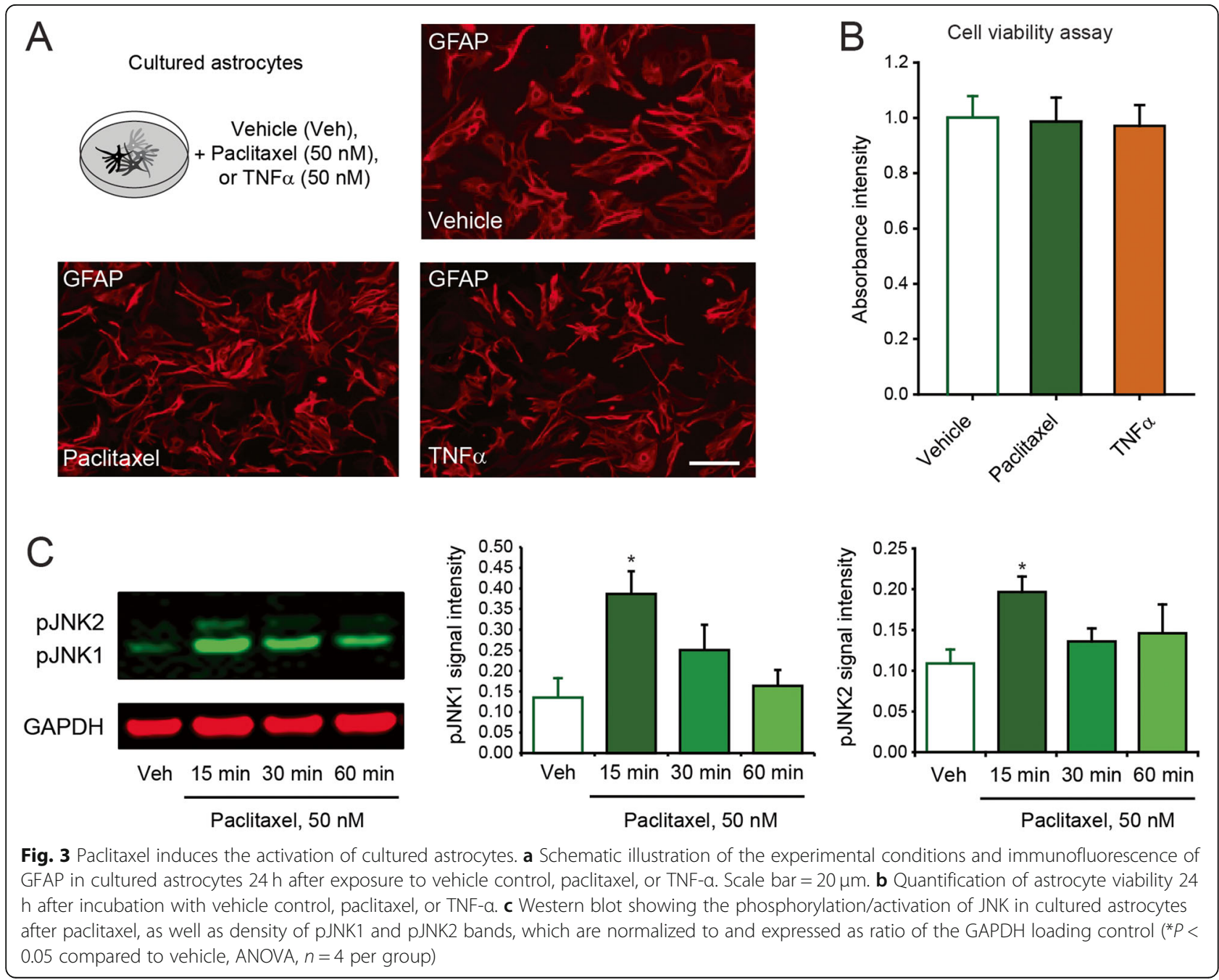


the quality of our cultured astrocytes (Fig. 3a) and demonstrated a comparable viability among vehicle-, paclitaxel-, and TNF $\alpha$-treated cultures (Fig. 3b). We then tested the phosphorylation of JNK, which has been previously involved in the activation of astrocytes by TNF- $\alpha$ and in the development of neuropathic pain [22, 42]. The expression levels of two main isoforms of pJNK (pJNK1 and pJNK2) were very low or absent in vehicletreated cultures. However, paclitaxel treatment induced a rapid, although transient, activation (phosphorylation) of JNK1 and JNK2 (Fig. 3c). This phosphorylation appeared to be more prominent for JNK1 and reached to a peak within $15 \mathrm{~min}$, similarly to what was observed for TNF- $\alpha$ [22]. Although paclitaxel has been suggested to engage TLR4 in microglia and neurons $[16,25]$, we found that activation of JNK was intact when the cultures were treated with the TLR4 inhibitor C34 [43] during the paclitaxel stimulation (Additional file 1: Figure S1). This is consistent with the report of the absence of TLR4 in cultured astrocytes [44]. Together, these results suggest that paclitaxel can activate astrocytes via the phosphorylation of JNK, but they probably engage different and TLR4 independent signaling pathways than neurons.

\section{Paclitaxel and TNF- $a$ induce different cytokines in cultured astrocytes}

Microtubule stabilizers such as paclitaxel can change directly the expression and distribution of GFAP and indirectly regulate the astrocytic glutamate transporters that may be responsible for increases in synaptic transmission and paclitaxel-induced neuropathic pain $[18,45]$. However, no or minimal transcriptional changes were observed in cultured astrocytes after paclitaxel and TNF- $\alpha$ exposure ( $50 \mathrm{nM}$ for $6 \mathrm{~h}$ or $24 \mathrm{~h}$ ) for GFAP, as well as GLAST and GLT-1 (Fig. 4a), two glutamate transporters that are implicated in neuropathic pain and are expressed predominantly in astrocytes $[18,46]$. Interestingly, GLAST is temporary downregulated at $6 \mathrm{~h}$ partially mimicking previous findings in vivo $[18,45]$. Activation of JNK in astrocytes by TNF- $\alpha$ plays an important role in the expression of pro-inflammatory cytokines contributing to neuropathic pain [22, 32]. Although transcriptional analyses of cultured astrocytes showed no changes in proinflammatory cytokines such as interleukin (IL)- $1 \beta$ and IL-6, a significant decreased for TNF- $\alpha$ was observed after paclitaxel exposure (Fig. 4b). To note, all these proinflammatory cytokines were increased in cultured astrocytes after TNF- $\alpha$ exposure (Fig. 4b). The significant decrease of TNF- $\alpha$ after paclitaxel prompted us to ask whether post-transcriptional changes would regulate cytokines and chemokines after exposure to paclitaxel. We found by ELISA that the protein levels of TNF- $\alpha$ were significantly increased after paclitaxel, suggesting indeed compensatory post-transcriptional changes (Fig. 4c). We also performed a preliminary screening using a cytokine array (blot) that contains 40 different cytokine and chemokine antibodies (Additional file 2: Figure S2A). We

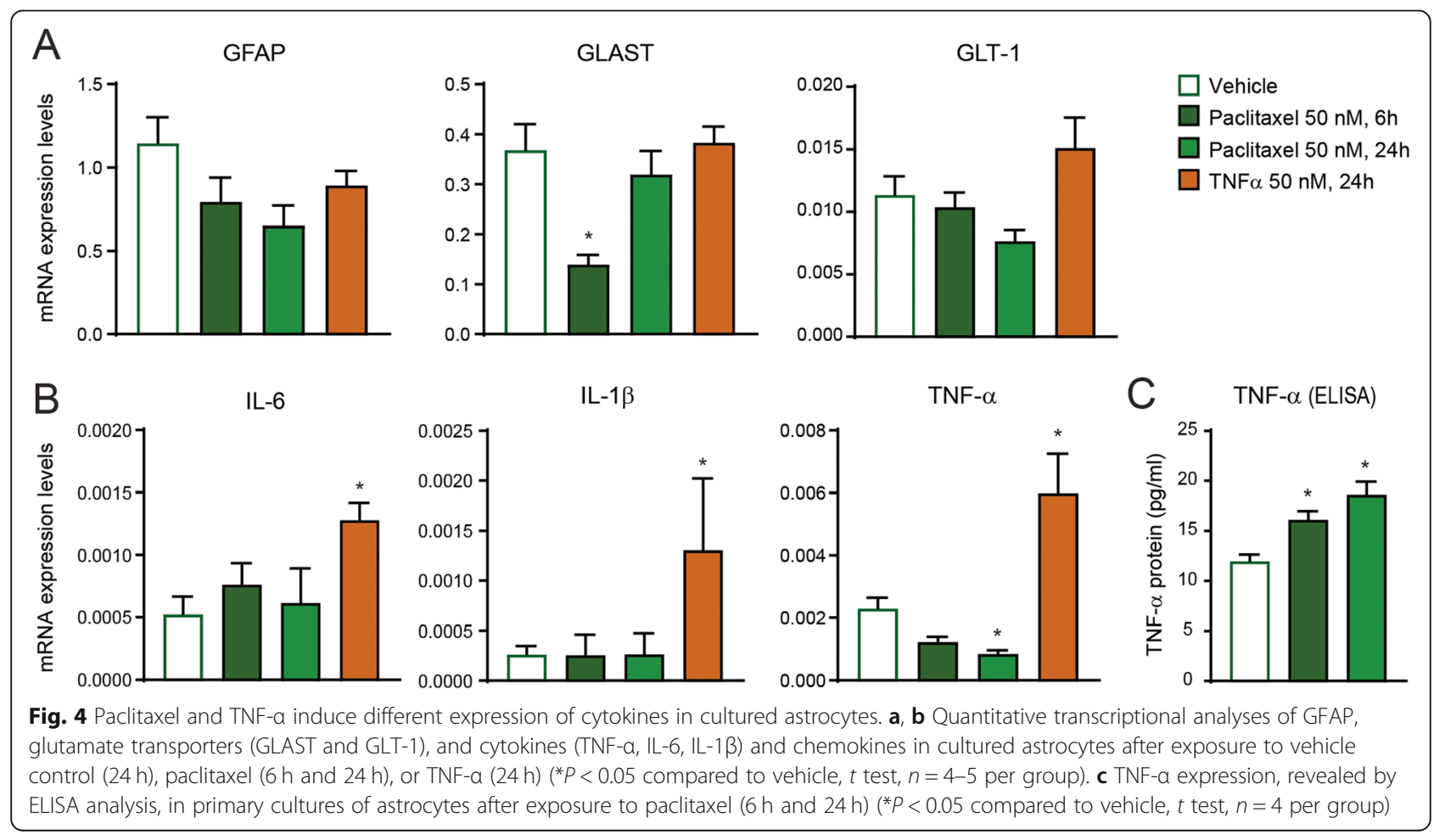


covered the blots with cell lysates from cultured astrocytes incubated with vehicle control or paclitaxel (Additional file 2: Figure S2B). In particular, incubation with paclitaxel induced modest but significant changes in TNF$\alpha$ (1.16-fold, $P<0.01)$ and stromal cell-derived factor 1 (SDF-1, alias CXCL12, 1.07-fold, $P<0.001$ ) (Additional file 2: Figure $\mathrm{S} 2 \mathrm{C}$ and Additional file 4: Table S2). The results suggest that brief exposure to paclitaxel regulates the post-transcriptional production of different cytokines in astrocytes. After this initial screening, we chose to further characterize TNF- $\alpha$ and SDF-1 since they are strongly implicated in astrocyte activation [47] in animal models of inflammatory and neuropathic pain [48-50].

\section{Intrathecal injection of paclitaxel-activated astrocytes elicit allodynia via TNF- $a$ and SDF-1}

To determine whether paclitaxel-activated astrocytes are sufficient to induced pain sensitization, we prepared cultured astrocytes, which were then stimulated with a vehicle control or paclitaxel (50 $\mathrm{nM}$ for $1 \mathrm{~h}$ or $6 \mathrm{~h}$ ). After harvesting these astrocytes, we washed them thoroughly three times with PBS to remove the paclitaxel and collected the astrocytes for intrathecal injection in naïve mice (Fig. 5a). We found a dramatic reduction in paw withdrawal threshold after intrathecal injection of paclitaxel-stimulated astrocytes, indicating the development of mechanical allodynia (Fig. 5b). This allodynia developed at $1 \mathrm{~h}$ and lasted for up to $6 \mathrm{~h}$. Notably, mice that received intrathecal injection of vehicle-stimulated did not develop mechanical allodynia (Fig. 5b). To test the hypothesis that paclitaxel-activated astrocytes release TNF- $\alpha$ and SDF-1 to generate tactile allodynia in naïve animals, we intrathecally injected a TNF- $\alpha$ or SDF-1 neutralizing antibody at $1 \mathrm{~h}$ after intrathecal injection of paclitaxel-activated astrocytes. At a dose $(5 \mu \mathrm{g} / \mathrm{site})$ that is effective in reducing glia-driven pain hypersensitivity [33], the TNF- $\alpha$ neutralizing antibody completely reversed mechanical allodynia induced by paclitaxel-
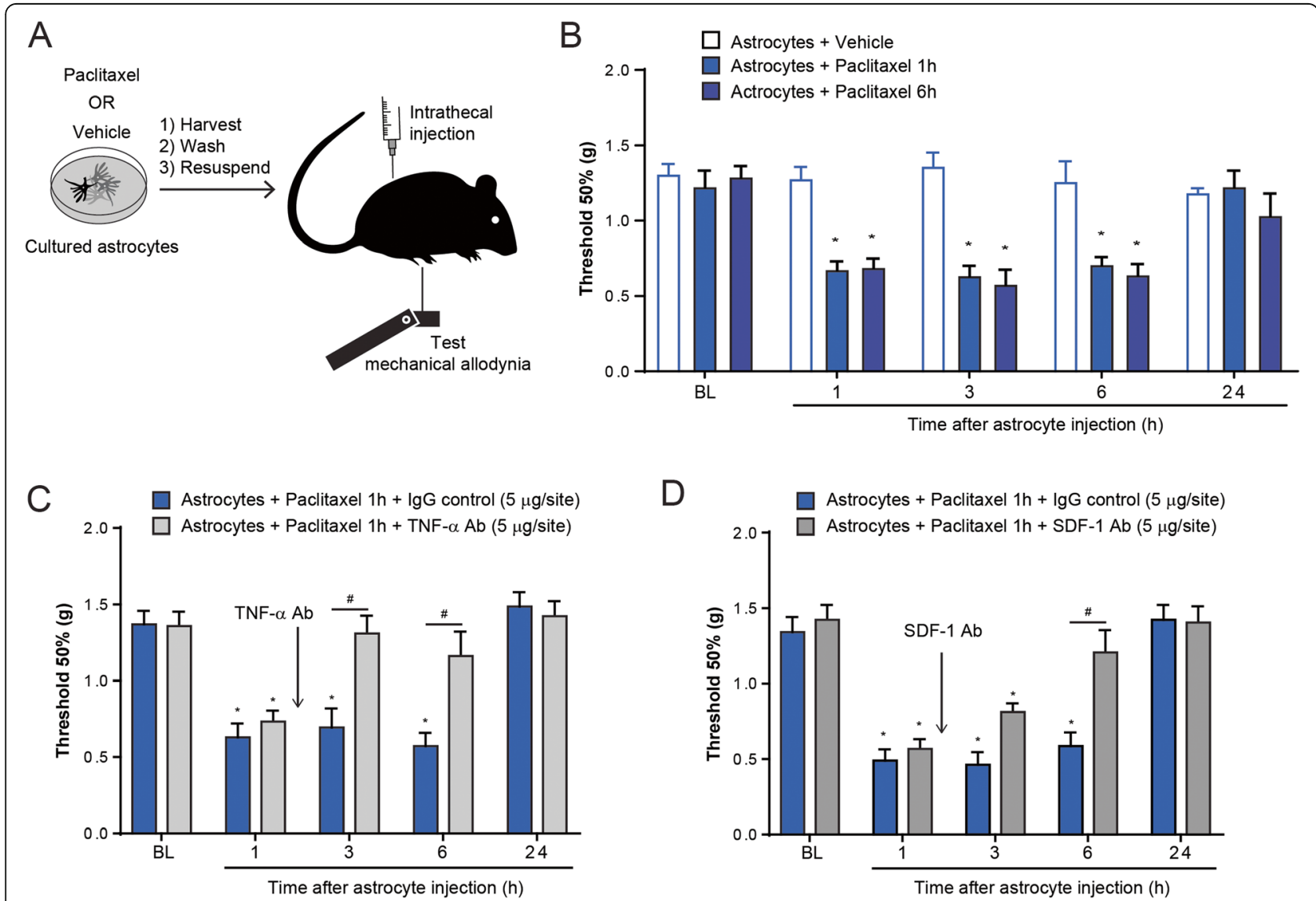

Fig. 5 Intrathecal injection of paclitaxel-activated astrocytes elicit allodynia via TNF-a and SDF-1. a Schematic illustration showing the experimental conditions of cultured astrocytes, intrathecal injection, and behavioral tests. $\mathbf{b}$ Effect of intrathecal (i.t.) injection of paclitaxelactivated astrocytes (astrocytes cultured with vehicle, paclitaxel for 1 or $6 \mathrm{~h}$ ) on mechanical allodynia in male mice ${ }^{*} P<0.05$ compared to vehicle, ANOVA, $n=5$ per group). $\mathbf{c}, \mathbf{d}$ Effect of intrathecal (i.t.) administration of TNF-a or SDF-1 neutralizing antibody on mechanical allodynia induced by i.t. injection of paclitaxel-activated astrocytes in male mice (astrocytes cultured with paclitaxel for $1 \mathrm{~h}, * 0<0.05$ compared to lgG control, ANOVA, $n=5$ per group) 
activated astrocytes (Fig. 5c). Similarly, SDF-1 neutralizing antibody $(5 \mu \mathrm{g} / \mathrm{site})$ also reversed mechanical allodynia induced by paclitaxel-activated astrocytes (Fig. 5d). In contrast, intrathecal injection of the control immunoglobulin G (IgG) had no effect on mechanical allodynia (Fig. 5c, d). Collectively, these results suggest that paclitaxel-activated astrocytes are sufficient to induce mechanical allodynia in naive mice, which is caused by the release of TNF- $\alpha$ and SDF-1.

\section{Discussion}

Paclitaxel is associated with acute pain syndrome for which the underlying mechanisms are poorly understood hampering the development of new and much needed therapeutic treatments. Here, we uncovered the role of spinal astrocytes for the development of mechanical allodynia in a preclinical model of P-APS and showed that intrathecal injections of low levels of paclitaxel or paclitaxel-activated astrocytes are sufficient to produce mechanical allodynia.

Activation of spinal microglia and astrocytes is emerging as key mechanism underlying chronic pain [15]. Activation of astrocytes has been shown to contribute to the development of chronic pain in various preclinical conditions including in animal models of chemotherapyinduced neuropathic pain. This activation is generally slow to develop and preceded by microglial reaction, which is known to drive astrocyte activation [14]. Although there is evidence supporting a role of microglia in chemotherapy-induced pain $[16,51,52]$, astrocytes can be rapidly activated in the apparent absence of microglia reaction after exposure to the chemotherapeutic agents paclitaxel, oxaliplatin, and bortezomib [18, 53]. Our results are in line with these observations and show that activation of astrocytes, which we assessed by upregulation of GFAP, occurs in few hours after a single systemic injection of paclitaxel. Furthermore, we also demonstrated that the mechanical allodynia associated with this activation is reversed by the astrocytic inhibitor L- $\alpha$-AA in both male and female mice. This result is in line with our previous study indicating sex-dependent microglial but not astrocytic signaling in the spinal cord in nerve injury-induced neuropathic pain [54]. The rapid upregulation of GFAP and analgesic effect of astrocytic inhibitors rise the question about how astrocyte activation occurs after delivery of paclitaxel.

Several studies have demonstrated that low levels ( 5-80 nM) of paclitaxel penetrate into the CSF and are detectable in the spinal cord in the initial hours and days of treatments in animals and patients $[24,25,55,56]$. Here, we show an upregulation of GFAP signal in the dorsal horn of the spinal cord, but we have also observed a strong signal in the areas around the central canal and in white matter. How astrocytes in these areas can participate to pain is still unclear, but extracellular mediators such cytokines can diffuse through the spinal cord and CSF and mediate pain processing. For instance, intrathecal administration of TNF- $\alpha$ elicits pain $[22,57]$ or cervical increase of TNF- $\alpha$ induces mechanical allodynia in rodent hind paws [58]. Interestingly, the strong GFAP signal in these areas, which are highly exposed to the CSF, may indicate that amounts of paclitaxel which penetrate into the CSF can be sufficient to directly activate astrocytes and thus elicit P-APS. It has been reported that paclitaxel in CSF and spinal cord tissue can direct the development and progress of P-APS [56]. Here, we used a concentration of $50 \mathrm{nM}$ of paclitaxel that was previously reported in the CSF patients after a single intravenous injection of paclitaxel [59] and acute application shown to increased synaptic transmission in rat spinal cord slices [25]. Using this concentration, we show that intrathecal injection into the intrathecal space of a small amount of paclitaxel is sufficient to induce mechanical allodynia, which is reversed by the astrocytic inhibitor L- $\alpha$-AA. Previous study showed that phosphorylation of ERK and, in particular, JNK in spinal astrocytes plays an important role in neuropathic pain [14]. Both inhibition of ERK and JNK reduced this paclitaxelinduced mechanical allodynia, suggesting a major participation of astrocytic signaling to P-APS. We and other groups have reported the development of cold allodynia in mice receiving systemic injections of paclitaxel [26, $60,61]$. Interestingly, our intrathecal injection of paclitaxel failed to replicate this particular allodynia. Recently, it has been suggested that peripheral sensory neurons are essential for cold allodynia, whereas mechanical allodynia is mostly dependent on the activation of the immune system after peripheral nerve injury [62]. Although it is tempting to conclude from this study and our behavioral results that our intrathecal injection of paclitaxel mostly targets and activates non-neuronal cells such as astrocytes, we cannot exclude that this intrathecal drug administration may also impact the activity of other cells in the spinal cord and dorsal root ganglia. It is therefore possible that the aforementioned behaviors can be only partially driven by astrocytes.

To determine the direct and exclusive role of paclitaxel in astrocytes, we prepared primary cultures of astrocytes and mimic the in vivo conditions of astrocytes with brief exposure to low amount of paclitaxel. It has been demonstrated that p-JNK is increased in spinal astrocytes in chronic pain conditions, including after paclitaxel injections [20]. This increase is induced in vivo and in vitro by diverse stress-related stimuli and proinflammatory cytokines such as TNF- $\alpha[22,23]$. Although paclitaxel induces no major changes in the morphology and viability of cultured astrocytes, it significantly increased the expression of $\mathrm{p}$-JNK in minutes 
as previously reported in astrocytes stimulated with TNF- $\alpha$ [22]. In line with the predominant expression of JNK1 in astrocytes [22], we observed a stronger increase in the expression of this isoform after paclitaxel. Although paclitaxel has been suggested to engage TLR4 in microglia and neurons $[16,25]$, cultured astrocytes have been reported to lack the expression of TLR4 [44] and we found that activation of JNK was independent from TLR4. Further studies are needed to investigate how paclitaxel interacts with astrocytes. However, it has been reported that paclitaxel can change intermediate filaments including GFAP in various cells and can induce the activation of JNK pathway leading to the apoptosis of carcinoma cells $[45,63]$. The exact upstream mechanisms by which paclitaxel engages GFAP and JNK remain unclear and require further studies.

In contrast, JNK downstream signaling is well-known for engaging several transcriptional factors such as c-Jun and induces gene transcription in astrocytes [23]. However, no dramatic changes were observed by our transcriptional analysis of paclitaxel-treated astrocytes. We, as shown here, and others have observed that GFAP levels are increased in astrocytes of mice injected with paclitaxel $[18,20]$, and it has been reported that paclitaxel induces early downregulation of multiple glutamate transporters [18]. However, we found that only GLAST mRNA is temporarily decreased in cultured astrocytes 6 $\mathrm{h}$ after paclitaxel. It is therefore possible that these transporters are posttranscriptionally regulated or in vivo astrocytes received additional inputs from other cells causing additional changes. This is a clear limitation of our study, and it should be further investigated in follow-up studies. It is also surprising that TNF- $\alpha$ - and paclitaxel-treated astrocytes present similar pJNK activation [22], but robust transcriptional increases in proinflammatory cytokines are only observed in TNF- $\alpha-$ treated astrocytes. However, these results are in line with a previous report showing no transcriptional changes for IL- $1 \beta$, IL-6, and TNF- $\alpha$ in the spinal cord tissue after paclitaxel [18]. Changes in pro-inflammatory cytokines can occur at translational levels. Indeed, recent studies have reported increased TNF- $\alpha$ and IL- $1 \beta$ in the spinal cord tissues and astrocytes in mice treated with various chemotherapeutic agents, including paclitaxel $[19,21,64]$.

Our data shows that TNF- $\alpha$ and SDF-1 proteins are seemingly increased in and released by paclitaxelactivated astrocytes into CSF and spinal cord tissue. TNF- $\alpha$ is an essential trigger of inflammatory cascades that underline the pathogenesis of pain. TNF- $\alpha$ can directly and rapidly enhance excitatory synaptic transmission in dorsal horn neurons [65] and can also further activates glial cells $[22,66]$. Interestingly, spinal administration of TNF- $\alpha$ is sufficient to induce mechanical allodynia [22, 57], and systemic injection of TNF- $\alpha$ inhibitor etanercept significantly attenuated paclitaxel-established mechanical and cold allodynia by putative actions on both peripheral and central TNF- $\alpha$ signaling $[17,67]$. Similarly, blockade of SDF-1 signaling ameliorated the paclitaxel-induced mechanical allodynia [50]. Consistently, SDF-1 is produced by glial cells and neurons in the central nervous system [68], and epigenetic upregulation of SDF-1 expression has been demonstrated in mice receiving paclitaxel injections [50]. Of note, it has been reported that TNF- $\alpha$ promotes the activation of NF- $\kappa B$ by SDF-1 [47] that can sustain the production of pro-inflammatory cytokines underlying the development and progression of paclitaxel-induced neuropathic pain $[19,21,64,69]$.

Paclitaxel has been suggested to elicit pain by engaging microglia and neurons via TLR4 $[16,25]$. However, we have showed that the astrocytic inhibitor L- $\alpha$-AA significantly attenuated P-APS and found that paclitaxelinduced activation of astrocytes was independent from TLR4. Furthermore, recent evidence suggests that activation of astrocytes may be sufficient to produce pain. We have previously reported that spinal injection of TNF- $\alpha$ activated astrocytes produces a robust mechanical allodynia by the release of MCP-1 [32]. Here, we provide direct evidence that intrathecal injection of paclitaxelactivated astrocytes is sufficient to induce mechanical allodynia compared to injection of control astrocytes. Furthermore, we demonstrate the functional role of the release of pro-inflammatory cytokines from paclitaxelactivated astrocytes since the mechanical allodynia induced by these astrocytes is reversed by both TNF- $\alpha$ and SDF-1 neutralizing antibodies. It remains to be investigated whether paclitaxel-activated astrocytes may also activate other spinal cells (e.g., microglia or oligodendrocytes) to increase the release of the pro-inflammatory cytokines and thus actively participate to induce this mechanical allodynia. Perhaps, it is also important that there is an apparent delay in the analgesic action of the SDF-1 antibody compared to the TNF- $\alpha$ neutralizing antibody, raising the possibility that TNF- $\alpha$ release precedes and controls SDF-1 production [47] and thus may represent a better therapeutic target for the treatment of paclitaxel-associated pain.

\section{Conclusion}

In the present study, we have demonstrated that astrocytes are involved in the development of paclitaxelassociated acute pain syndrome. We have also established that paclitaxel directly activates astrocytes, and paclitaxel-activated astrocytes are sufficient to induce mechanical allodynia via TNF- $\alpha$ and SDF-1. Future studies should be conducted to investigate whether other chemotherapeutic agents or multiple injections of paclitaxel recapitulate and further activate astrocytes or other 
cells by engaging similar signaling. However, it is now clear that paclitaxel not only accumulates in dorsal root ganglia [70] but also penetrates the CSF and spinal cord tissue where it can directly activate astrocytes and cause pain. Therefore, future therapeutic approaches aiming to reduce paclitaxel-associated pain might be made more effective by targeting both peripheral and central pathological changes.

\section{Supplementary information}

Supplementary information accompanies this paper at https://doi.org/10. 1186/s12974-019-1619-9.

Additional file 1: Figure S1. Paclitaxel induces the activation of JNK in cultured astrocytes independently from TLR4 signaling. Western blot showing the phosphorylation/activation of JNK in cultured astrocytes 15 min after paclitaxel, as well as density of pJNK1, pJNK2 bands, which are normalized to and expressed as ratio of the GAPDH loading control (C34 = TLR4 inhibitor TLR4-IN-C34, ANOVA, $n=4$ per group).

Additional file 2: Figure S2. Cytokine array indicates potential regulation of chemokines in astrocytes after paclitaxel exposure. A Illustration of the cytokine array with 40 cytokines in duplicates (PC = positive control). B and C, Blot arrays and volcano plot reveal the protein regulation of various cytokines such TNF- $\mathrm{a}$ and SDF-1 $24 \mathrm{~h}$ after exposure to paclitaxel $(P<0.05$ compared to vehicle, t-test, $n=2$ assays, 4 samples were pooled together see methods).

Additional file 3: Table S1. qPCR primer sequences.

Additional file 4: Table S2. Volcano plot data.

\section{Abbreviations}

CSF: Cerebrospinal fluid; ERK: Extracellular signal-regulated kinase; GFAP: Glial fibrillary acidic protein; JNK: c-Jun N-terminal kinase; L-a-AA: L-aaminoadipate; MCP-1: Monocyte chemoattractant protein-1; PACP: Paclitaxel-associated acute pain syndrome; SDF-1: Stromal cell-derived factor 1; TNF-a: Tumor necrosis factor alpha

\section{Acknowledgements}

Not applicable.

\section{Authors' contributions}

$\mathrm{XL}$ and RT participated to the design of the experiments, performed the experimental work and data analyses, and wrote part of the manuscript. YL participated in the experimental work and transcriptional analyses. TB and YJG supported and supervised the study, as well as wrote and edited the manuscript. All authors read and approved the final manuscript.

\section{Funding}

This work was partially funded by the NIH/NINDS grants NS106264 and NS113243 to TB, as well as the 14th Six Talents Peak Project of Jiangsu Province (No. SWYY-058) to XL and to the National Natural Science Foundation of China grants 31871064 and 31671091 to YJG.

\section{Availability of data and materials}

Please contact author for raw data requests.

\section{Ethics approval and consent to participate}

Not applicable.

\section{Consent for publication}

Not applicable.

\section{Competing interests}

The authors declare that they have no competing interests.

\section{Author details}

${ }^{1}$ Department of Anesthesiology, Pain Research Center, University of Cincinnati College of Medicine, Cincinnati, OH, USA. ${ }^{2}$ Department of Pathogen Biology, Medical College, Nantong University, Nantong, Jiangsu, China. ${ }^{3}$ Institute of Pain Medicine, Nantong University, Nantong, Jiangsu, China. ${ }^{4}$ Institute of Special Environmental Medicine, Nantong University, Nantong, Jiangsu, China.

Received: 8 March 2019 Accepted: 18 October 2019

Published online: 10 November 2019

\section{References}

1. Dougherty PM, Cata JP, Cordella JV, Burton A, Weng HR. Taxol-induced sensory disturbance is characterized by preferential impairment of myelinated fiber function in cancer patients. Pain. 2004;109:132-42.

2. Loprinzi CL, Reeves BN, Dakhil SR, Sloan JA, Wolf SL, Burger KN, et al. Natural history of paclitaxel-associated acute pain syndrome: prospective cohort study NCCTG N08C1. J Clin Oncol. 2011:29:1472-8.

3. Reeves BN, Dakhil SR, Sloan JA, Wolf SL, Burger KN, Kamal A, et al. Further data supporting that paclitaxel-associated acute pain syndrome is associated with development of peripheral neuropathy. Cancer. 2012:118:5171-8.

4. Seretny M, Currie GL, Sena ES, Ramnarine S, Grant R, Macleod MR, et al. Incidence, prevalence, and predictors of chemotherapy-induced peripheral neuropathy: a systematic review and meta-analysis. Pain. 2014;155:2461-70.

5. Moulder SL, Holmes FA, Tolcher AW, Thall P, Broglio K, Valero V, et al. A randomized phase 2 trial comparing 3-hour versus 96-hour infusion schedules of paclitaxel for the treatment of metastatic breast cancer. Cancer. 2010;116:814-21.

6. Cascella M. Chemotherapy-induced peripheral neuropathy: limitations in current prophylactic strategies and directions for future research. Curr Med Res Opin. 2017;33:981-4.

7. Ma J, Kavelaars A, Dougherty PM, Heijnen CJ. Beyond symptomatic relief for chemotherapy-induced peripheral neuropathy: targeting the source. Cancer. 2018:124:2289-98.

8. Sisignano M, Baron R, Scholich K, Geisslinger G. Mechanism-based treatment for chemotherapy-induced peripheral neuropathic pain. Nat. Rev. Neurol. 2014;10:694-707.

9. Bennett GJ, Doyle T, Salvemini D. Mitotoxicity in distal symmetrical sensory peripheral neuropathies. Nat Rev Neurol. 2014;10:326-36.

10. Carozzi VA, Canta A, Chiorazzi A. Chemotherapy-induced peripheral neuropathy: what do we know about mechanisms? Neurosci. Lett. 2015;596: 90-107.

11. Loprinzi CL, Maddocks-Christianson K, Wolf SL, Rao RD, Dyck PJB, Mantyh P, et al. The paclitaxel acute pain syndrome: sensitization of nociceptors as the putative mechanism. Cancer J. 2007;13:399-403.

12. Flatters SJL, Xiao WH, Bennett GJ. Acetyl-L-carnitine prevents and reduces paclitaxel-induced painful peripheral neuropathy. Neurosci Lett. 2006:397:219-23.

13. Authier N, Gillet JP, Fialip J, Eschalier A, Coudore F. Description of a shortterm Taxol-induced nociceptive neuropathy in rats. Brain Res. 2000:887:239-49.

14. Ji RR, Berta T, Nedergaard M. Glia and pain: is chronic pain a gliopathy? Pain. 2013:154:S10-28.

15. Grace PM, Hutchinson MR, Maier SF, Watkins LR. Pathological pain and the neuroimmune interface. Nat Rev Immunol. 2014;14:217-31.

16. Yan X, Li F, Maixner DW, Yadav R, Gao M, Ali MW, et al. Interleukin-1 beta released by microglia initiates the enhanced glutamatergic activity in the spinal dorsal horn during paclitaxel-associated acute pain syndrome. Glia. 2019:67:482-97.

17. Wu Z, Wang S, Wu I, Mata M, Fink DJ. Activation of TLR-4 to produce tumour necrosis factor-a in neuropathic pain caused by paclitaxel. Eur J Pain. 2015:19:889-98.

18. Zhang HH, Yoon SY, Zhang HH, Dougherty PM. Evidence that spinal astrocytes but not microglia contribute to the pathogenesis of paclitaxelinduced painful neuropathy. J Pain. 2012;13:293-303.

19. Janes K, Wahlman C, Little JW, Doyle T, Tosh DK, Jacobson KA, et al. Spina neuroimmune activation is independent of T-cell infiltration and attenuated by $\mathrm{A} 3$ adenosine receptor agonists in a model of oxaliplatin-induced peripheral neuropathy. Brain Behav Immun. 2015;44:91-9. 
20. Xu Y, Cheng G, Zhu Y, Zhang X, Pu S, Wu J, et al. Anti-nociceptive roles of the glia-specific metabolic inhibitor fluorocitrate in paclitaxel-evoked neuropathic pain. Acta Biochim Biophys Sin (Shanghai). 2016;48:902-8.

21. Ji XT, Qian NS, Zhang T, Li JM, Li XK, Wang P, et al. Spinal astrocytic activation contributes to mechanical allodynia in a rat chemotherapyinduced neuropathic pain model. PLoS One. 2013;8(4):e60733. https://doi. org/10.1371/journal.pone.0060733. Print 2013. PMID: 23585846.

22. Gao Y-J, Zhang L, Samad OA, Suter MR, Yasuhiko K, Xu Z-Z, et al. JNKinduced MCP-1 production in spinal cord astrocytes contributes to central sensitization and neuropathic pain. J Neurosci. 2009;29:4096-108.

23. Zhuang Z-Y, Wen Y-R, Zhang D-R, Borsello T, Bonny C, Strichartz GR, et al. A peptide c-Jun N-terminal kinase (JNK) inhibitor blocks mechanical allodynia after spinal nerve ligation: respective roles of JNK activation in primary sensory neurons and spinal astrocytes for neuropathic pain development and maintenance. J Neurosci. 2006;26:3551-60.

24. Cavaletti G, Cavalletti E, Oggioni N, Sottani C, Minoia C, D'Incalci M, et al. Distribution of paclitaxel within the nervous system of the rat after repeated intravenous administration. Neurotoxicology. 2000;21:389-93.

25. Li Y, Adamek $P$, Zhang H, Tatsui CE, Rhines LD, Mrozkova $P$, et al. The cancer chemotherapeutic paclitaxel increases human and rodent sensory neuron responses to TRPV1 by activation of TLR4. J Neurosci. 2015;35:13487-500.

26. Tonello R, Lee SH, Berta T. Monoclonal antibody targeting the matrix metalloproteinase 9 prevents and reverses paclitaxel-induced peripheral neuropathy in mice. J Pain. 2019;20:515-27.

27. Duggett NA, Griffiths LA, Flatters SJL. Paclitaxel-induced painful neuropathy is associated with changes in mitochondrial bioenergetics, glycolysis, and an energy deficit in dorsal root ganglia neurons. Pain. 2017;158:1499-508.

28. Krukowski K, Eijkelkamp N, Laumet G, Hack CE, Li Y, Dougherty PM, et al. CD8 $+T$ cells and endogenous $\mathrm{L}-10$ are required for resolution of chemotherapy-induced neuropathic pain. J Neurosci. 2016;36:11074-83.

29. Chaplan SR, Bach FW, Pogrel JW, Chung JM, Yaksh TL. Quantitative assessment of tactile allodynia in the rat paw. J Neurosci Methods. 1994;53:55-63.

30. Dixon WJ. Efficient analysis of experimental observations. Annu Rev Pharmacol Toxicol. 1980;20:441-62.

31. Brenner DS, Golden JP, Gereau RW IV. A novel behavioral assay for measuring cold sensation in mice. PLoS One. 2012;7(6):e39765. https://doi. org/10.1371/journal.pone.0039765. Epub 2012 Jun 22. PMID: 22745825

32. Gao YJ, Zhang L, Ji RR. Spinal injection of TNF-a-activated astrocytes produces persistent pain symptom mechanical allodynia by releasing monocyte chemoattractant protein-1. Glia. 2010;58:1871-80.

33. Berta T, Park C-KK XZ-ZZ, Xie R-GG, Liu T, Lü N, et al. Extracellular caspase-6 drives murine inflammatory pain via microglial TNF-a secretion. J Clin Invest. 2014;124:1173-86

34. Lee SH, Cho PS, Tonello R, Lee HK, Jang JH, Park GY, et al. Peripheral serotonin receptor $2 \mathrm{~B}$ and transient receptor potential channel 4 mediate pruritus to serotonergic antidepressants in mice. J Allergy Clin Immunol. 2018;142:1349-52 e16.

35. Zhuang ZY, Gerner P, Woolf CJ, Ji RR. ERK is sequentially activated in neurons, microglia, and astrocytes by spinal nerve ligation and contributes to mechanical allodynia in this neuropathic pain model. Pain. 2005;114:149-59.

36. Jiang B-CC, Cao D-LL, Zhang X, Zhang Z-JJ, He L-NN, Li C-HH, et al. CXCL13 drives spinal astrocyte activation and neuropathic pain via CXCR5. J Clin Invest. 2016;126:745-61.

37. Wang X, Spandidos A, Wang H, Seed B. PrimerBank: a PCR primer database for quantitative gene expression analysis, 2012 update. Nucleic Acids Res. 2012:40:D1144-9.

38. Pfaffl MW. A new mathematical model for relative quantification in real-time RT-PCR. Nucleic Acids Res. 2001;29:45e-45.

39. Berta T, Poirot O, Pertin M, Ji RR, Kellenberger S, Decosterd I. Transcriptional and functional profiles of voltage-gated $\mathrm{Na}+$ channels in injured and noninjured DRG neurons in the SNI model of neuropathic pain. Mol Cell Neurosci. 2008;37:196-208.

40. Gao YJ, Ji RR. Light touch induces ERK activation in superficial dorsal horn neurons after inflammation: involvement of spinal astrocytes and JNK signaling in touch-evoked central sensitization and mechanical allodynia. $J$ Neurochem. 2010;115:505-14.

41. Xiao WH, Zheng H, Zheng FY, Nuydens R, Meert TF, Bennett GJ. Mitochondrial abnormality in sensory, but not motor, axons in paclitaxel-evoked painful peripheral neuropathy in the rat. Neuroscience. 2011;199:461-9.
42. Gao YJ, Ji RR. Targeting astrocyte signaling for chronic pain. Neurotherapeutics. 2010;7:482-93.

43. Neal MD, Jia H, Eyer B, Good M, Guerriero CJ, Sodhi CP, et al. Discovery and validation of a new class of small molecule Toll-like receptor 4 (TLR4) inhibitors. PLoS One. 2013;8:e65779.

44. Liddelow SA, Guttenplan KA, Clarke LE, Bennett FC, Bohlen CJ, Schirmer L, et al. Neurotoxic reactive astrocytes are induced by activated microglia. Nature. 2017:541:481-7.

45. Goetschy JF, Ulrich G, Aunis D, Ciesielski-Treska J. The organization and solubility properties of intermediate filaments and microtubules of cortical astrocytes in culture. J Neurocytol. 1986;15:375-87.

46. Xin WJ, Weng HR, Dougherty PM. Plasticity in expression of the glutamate transporters GLT-1 and GLAST in spinal dorsal horn glial cells following partial sciatic nerve ligation. Mol Pain. 2009;5:1744-8069 5-15.

47. Han Y, He T, Huang DR, Pardo CA, Ransohoff RM. TNF-alpha mediates SDF-1 alpha-induced NF-kappa B activation and cytotoxic effects in primary astrocytes. J Clin Invest. 2001;108:425-35.

48. Shen W, Hu X-M, Liu Y-N, Han Y, Chen L-P, Wang C-C, et al. CXCL12 in astrocytes contributes to bone cancer pain through CXCR4-mediated neuronal sensitization and glial activation in rat spinal cord. J Neuroinflammation. 2014:11:75-89.

49. Zhang L, Berta T, Xu Z-Z, Liu T, Park JY, Ji R-R. TNF-a contributes to spinal cord synaptic plasticity and inflammatory pain: distinct role of TNF receptor subtypes 1 and 2. Pain. 2011;152:419-27.

50. Xu T, Zhang XL, Ou-Yang HD, Li ZY, Liu CC, Huang ZZ, et al. Epigenetic upregulation of CXCL12 expression mediates antitubulin chemotherapeutics-induced neuropathic pain. Pain. 2017;158:637-48.

51. Di Cesare ML, Pacini A, Bonaccini L, Zanardelli M, Mello T, Ghelardini C. Morphologic features and glial activation in rat oxaliplatin-dependent neuropathic pain. J Pain. 2013;14:1585-600.

52. Wu J, Hocevar M, Bie B, Foss JF, Naguib M. Cannabinoid type 2 receptor system modulates paclitaxel-induced microglial dysregulation and central sensitization in rats. J Pain. 2019;20:501-14.

53. Robinson CR, Zhang H, Dougherty PM. Astrocytes, but not microglia, are activated in oxaliplatin and bortezomib-induced peripheral neuropathy in the rat. Neuroscience. 2014;274:308-17.

54. Chen G, Luo X, Qadri MY, Berta T, Ji RR. Sex-dependent glial signaling in pathological pain: distinct roles of spinal microglia and astrocytes. Neurosci Bull. 2018;34:98-108.

55. Xiao WH, Bennett GJ. Chemotherapy-evoked neuropathic pain: abnormal spontaneous discharge in A-fiber and C-fiber primary afferent neurons and its suppression by acetyl-I-carnitine. Pain. 2008;135:262-70.

56. Yan X, Maixner DW, Yadav R, Gao M, Li P, Bartlett MG, et al. Paclitaxel induces acute pain via directly activating toll like receptor 4. Mol Pain. 2015;11.

57. Kawasaki Y, Xu Z-Z, Wang X, Park JY, Zhuang Z-Y, Tan P-H, et al. Distinct roles of matrix metalloproteases in the early- and late-phase development of neuropathic pain. Nat Med. 2008;14:331-6.

58. Martini AC, Berta T, Forner S, Chen G, Bento AF, Ji R-R, et al. Lipoxin A4 inhibits microglial activation and reduces neuroinflammation and neuropathic pain after spinal cord hemisection. J Neuroinflammation. 2016;13:75.

59. Glantz MJ, Choy H, Kearns CM, Mills PC, Wahlberg LU, Zuhowski EG, et al. Paclitaxel disposition in plasma and central nervous systems of humans and rats with brain tumors. J Natl Cancer Inst. 1995;87:1077-81.

60. Peters CM, Jimenez-Andrade JM, Jonas BM, Sevcik MA, Koewler NJ, Ghilardi $J R$, et al. Intravenous paclitaxel administration in the rat induces a peripheral sensory neuropathy characterized by macrophage infiltration and injury to sensory neurons and their supporting cells. Exp Neurol. 2007;203:42-54.

61. Materazzi S, Fusi C, Benemei S, Pedretti P, Patacchini R, Nilius B, et al. TRPA1 and TRPV4 mediate paclitaxel-induced peripheral neuropathy in mice via a glutathione-sensitive mechanism. Pflugers Arch. 2012;463:561-9.

62. Cobos EJ, Nickerson CA, Gao F, Chandran V, Bravo-Caparrós I, GonzálezCano R, et al. Mechanistic differences in neuropathic pain modalities revealed by correlating behavior with global expression profiling. Cell Rep. 2018:22:1301-12.

63. Wang TH, Popp DM, Wang HS, Saitoh M, Mural JG, Henley DC, et al. Microtubule dysfunction induced by paclitaxel initiates apoptosis through both c-Jun N-terminal kinase (JNK)-dependent and -independent pathways in ovarian cancer cells. J Biol Chem. 1999;274:8208-16.

64. Doyle T, Chen Z, Muscoli C, Bryant L, Esposito E, Cuzzocrea S, et al. Targeting the overproduction of peroxynitrite for the prevention and reversal of paclitaxel-induced neuropathic pain. J Neurosci. 2012;32:6149-60. 
65. Kawasaki Y, Zhang L, Cheng J-K, Ji R-R. Cytokine mechanisms of central sensitization: distinct and overlapping role of interleukin-1, interleukin-6, and tumor necrosis factor- in regulating synaptic and neuronal activity in the superficial spinal cord. J Neurosci. 2008:28:5189-94.

66. Svensson $\mathrm{Cl}$, Schäfers M, Jones TL, Powell H, Sorkin LS. Spinal blockade of TNF blocks spinal nerve ligation-induced increases in spinal P-p38. Neurosci Lett. 2005;379:209-13.

67. Al-Mazidi S, Alotaibi M, Nedjadi T, Chaudhary A, Alzoghaibi M, Djouhri L. Blocking of cytokines signalling attenuates evoked and spontaneous neuropathic pain behaviours in the paclitaxel rat model of chemotherapyinduced neuropathy. Eur J Pain. 2018;22:810-21.

68. Guyon A. CXCL12 chemokine and its receptors as major players in the interactions between immune and nervous systems. Front Cell Neurosci. 2014;8:65.

69. Kabata H, Artis D. Neuro-immune crosstalk and allergic inflammation. J Clin Invest. 2015;122:1142-51.

70. Jimenez-Andrade JM, Herrera MB, Ghilardi JR, Vardanyan M, Melemedjian OK, Mantyh PW. Vascularization of the dorsal root ganglia and peripheral nerve of the mouse: implications for chemical-induced peripheral sensory neuropathies. Mol Pain. 2008;4:1744-8069 4-10.

\section{Publisher's Note}

Springer Nature remains neutral with regard to jurisdictional claims in published maps and institutional affiliations.

- fast, convenient online submission

- thorough peer review by experienced researchers in your field

- rapid publication on acceptance

- support for research data, including large and complex data types

- gold Open Access which fosters wider collaboration and increased citations

- maximum visibility for your research: over $100 \mathrm{M}$ website views per year

At $\mathrm{BMC}$, research is always in progress.

Learn more biomedcentral.com/submissions 